\title{
CORRECTIONS
}

\section{Author Correction: Crop microbiome and sustainable agriculture}

\author{
Brajesh K. Singh (D, Pankaj Trivedi (D), Eleonora Egidi, Catriona A. Macdonald and Manuel Delgado-Baquerizo
}

Correction to: Nature Reviews Microbiology 18, 601-602 (2020) https://doi.org/10.1038/s41579-020-00446-y published online 09 October 2020. In the original version of this Comment article, FAO was incorrectly defined. This has now been corrected in the HTML and PDF versions of the manuscript. The authors apologize to readers for this error.

https://doi.org/10.1038/s41579-020-00483-7 I Published online 12 November 2020

(c) Springer Nature Limited 2020

\section{Author Correction: Plant-microbiome interactions: from community assembly to plant health}

Pankaj Trivedi(D), Jan E. Leach, Susannah G. Tringe (D), Tongmin Sa(1) and Brajesh K. Singh(1)

Correction to: Nature Reviews Microbiology 18, 607-621 (2020) https://doi.org/10.1038/s41579-020-0412-1 published online 12 August 2020.

In Figure 1 of this Review article, ascomycetes and basidiomycetes were incorrectly labelled in the figure key. This has now been corrected in the HTML and PDF versions of the manuscript. The authors apologize to readers for this error.

https://doi.org/10.1038/s41579-020-00490-8 I Published online 23 November 2020

(c) Springer Nature Limited 2020 